\title{
Exertional Desaturation and Prescription of Ambulatory Oxygen Therapy in Interstitial Lung Disease
}

\author{
Yet Hong Khor, Nicole SL Goh, Ian Glaspole, Anne E Holland, and Christine F McDonald
}

\begin{abstract}
BACKGROUND: Exertional desaturation is an important predictor of mortality in patients with interstitial lung disease. We evaluated the prevalence of exertional desaturation in subjects with interstitial lung disease and determined its relationship with the prescription of ambulatory oxygen therapy. METHODS: Our retrospective analysis examined prospectively collected data from interstitial lung disease registries of 2 Melbourne hospitals: Alfred Health and Austin Health. All patients with baseline the 6-min walk tests on room air were included. We evaluated the prescription of ambulatory oxygen therapy, up to 3 months after 6-min walk tests, among those with exertional desaturation. RESULTS: Of the 400 subjects, 214 (54\%) had exertional desaturation. The prevalence of desaturation increased with the severity of lung function impairment (FVC measurement: $33 \%$ for $>\mathbf{7 5 \%}$ predicted, $69 \%$ for $50-75 \%$ predicted, $86 \%$ for $<50 \%$ predicted; diffusing capacity of the lung for carbon monoxide measurement: $20 \%$ for $>55 \%$ predicted, $64 \%$ for $36-55 \%$ predicted, $93 \%$ for $\leq 35 \%$ predicted, $P<.001$ for both severity classifications). There was no difference in the prevalence of exertional desaturation among common disease subtypes $(P=.17)$. Among the desaturators, $14(7 \%)$ had resting hypoxemia and all were prescribed long-term oxygen therapy. Of the remaining 200 with exertional desaturation only, $58(29 \%)$ were prescribed ambulatory oxygen therapy. Multiple logistic regression showed independent associations between the ambulatory oxygen therapy prescription and shorter 6 -min walk distance $(P<.001)$ as well as worse FVC (\% predicted, $P=.037)$. CONCLUSIONS: Exertional desaturation is common in subjects with interstitial lung disease. More severely impaired exercise capacity and worse lung function are associated with the prescription of ambulatory oxygen therapy in interstitial lung disease. Key words: interstitial lung disease; pulmonary fibrosis; oxygen; exercise; hypoxemia. [Respir Care 2019;64(3):299-306. (C) 2019 Daedalus Enterprises]
\end{abstract}

\section{Introduction}

Interstitial lung disease (ILD) consists of a spectrum of diffuse parenchymal lung diseases of different etiologies.

Drs Khor, Goh, and McDonald are affiliated with the Department of Respiratory and Sleep Medicine, Austin Health, Heidelberg, Victoria, Australia and Institute for Breathing and Sleep, Heidelberg, Victoria, Australia. Drs Khor, Goh, and Glaspole are affiliated with the Department of Allergy, Immunology and Respiratory Medicine, Alfred Health, Melbourne, Victoria, Australia. Dr Glaspole is also affiliated with School of Medicine, Monash University, Melbourne, Victoria, Australia. Dr Holland Department of Physiotherapy, Alfred Health, Melbourne, Victoria, Australia. Department of Physiotherapy, La Trobe University, Melbourne, Victoria, Australia.

Dr Khor is supported by the National Health and Medical Research Council Postgraduate Scholarship.
Although the natural progression of these diseases varies, a significant proportion progress to extensive lung fibrosis, with progressive breathlessness, hypoxemia, and reduced exercise tolerance. Exertional desaturation is a cardinal feature of ILD

\footnotetext{
Dr Khor presented a version of this paper at the Congress of the Asia Pacific Society of Respirology 2017, held November 25, 2017, in Sydney, Australia, and at the American Thoracic Society International Conference 2018, May 20, 2018, in San Diego, California.

Dr Khor discloses relationships with Air Liquide, Boehringer Ingelheim, the National Health, and Medical Research Council. Dr Goh discloses relationships with Air Liquide and Boehringer Ingelheim. Dr Glaspole discloses relationships with Boehringer-Ingelheim; Roche; and Air Liquide. Dr Holland discloses relationships with Air Liquide and Boehringer Ingelheim. Dr McDonald discloses relationships with Boehringer Ingelheim, Novartis, GSK, Pfizer, Menarini, and Air Liquide.
} 
and is an important predictor of mortality. ${ }^{1-6}$ Exertional desaturation is also an independent predictor of dyspnea and reduced physical activity in ILD. ${ }^{5,7}$ However, the prevalence of exertional desaturation in ILD is unknown.

Although ambulatory oxygen therapy is commonly prescribed for patients with ILD and exertional desaturation with the aims of relieving dyspnea and improving quality of life and activity levels, little is known about the prescription of ambulatory oxygen therapy in practice. Recent guidelines for domiciliary oxygen therapy by the British Thoracic Society ${ }^{8}$ and the Thoracic Society of Australia and New Zealand ${ }^{9}$ do not recommend routine prescription of ambulatory oxygen therapy for patients with exertional desaturation but without resting hypoxemia. Acute administration of oxygen therapy has been shown to improve exercise capacity during exercise tests in patients with ILD. ${ }^{10,11}$ A recent short-term non-blinded crossover trial in patients with ILD indicated potential improvement of quality of life with the use of ambulatory oxygen therapy. ${ }^{12}$ However, the long-term effects of ambulatory oxygen therapy in patients with ILD and exertional desaturation have not been evaluated. To optimize patient care in ILD, it is important to understand the burden of exertional desaturation and associated prescription of ambulatory oxygen therapy. This study aimed to evaluate the prevalence of exertional desaturation in this population. Further, we sought to determine the characteristics of patients with ILD and exertional desaturation who were prescribed ambulatory oxygen therapy.

\section{Methods}

This retrospective study was conducted by using the prospective ILD registries of 2 hospitals in Melbourne, Australia: Alfred Health (between October 2010 and January 2017) and Austin Health (between February 2015 and January 2017). Both hospitals have specialized ILD clinics, and 6-min walk tests (6MWT) are routinely conducted as part of the initial clinical assessment. All consenting patients are included in the registries regardless of diagnosis. We identified consecutive patients ages $\geq 18 \mathrm{y}$ with a diagnosis of ILD based on multidisciplinary evaluation and had completed baseline 6MWTs on room air.

Supplementary material related to this paper is available at http:// www.rcjournal.com.

Correspondence: Yet Hong Khor MD, Department of Respiratory and Sleep Medicine, Austin Health, 145 Studley Road, Heidelberg, Victoria, Australia 3084. E-mail: yethong.khor@ austin.org.au.

DOI: $10.4187 /$ respcare. 06334

\section{QUICK LOOK:}

\section{Current Knowledge:}

Exertional desaturation is an important prognostic factor in interstitial lung disease. In addition, exertional desaturation has been shown to be associated with breathlessness and impaired exercise capacity in this population. Despite its clinical and prognostic significance, the prevalence of exertional desaturation and associated prescription of ambulatory oxygen therapy in interstitial lung disease is unknown.

\section{What This Paper Contributes To Our Knowledge:}

We demonstrated that exertional desaturation was common in subjects with interstitial lung disease, even in those with mild physiologic impairment. The prescription of ambulatory oxygen therapy in this population is related to lung function and exercise capacity.

Data collected included baseline demographics, smoking history, comorbid conditions, lung function tests, 6MWT, symptom measurements (dyspnea, measured by using the modified Medical Research Council dyspnea scale and the University of California San Diego Shortness of Breath Questionnaire); health-related quality of life, measured by using the St George Respiratory Questionnaire; and a prescription of oxygen therapy (up to 3 months after 6MWTs). Prescribing criteria for oxygen therapy are based on the guidelines from the Thoracic Society of Australia and New Zealand (see the supplementary materials at http://www.rcjournal.com). ${ }^{9}$ This study was approved by the Alfred Hospital Ethics Committee (608/16) and the Austin Health Human Research Ethics Committee (LNR/16/Austin/347).

\section{MWT}

The 6MWTs were conducted according to the European Respiratory Society/American Thoracic Society guidelines. ${ }^{13}$ Two tests were performed at Alfred Health, whereas only 1 test was performed at Austin Health. Exertional desaturation was defined as a fall in oxyhemoglobin saturation $\left(\mathrm{S}_{\mathrm{pO}_{2}}\right)$ to $\leq 88 \%$, measured by using a continuous lightweight pulse oximeter. ${ }^{2,4}$

\section{Statistical Analysis}

Statistical analyses were performed by using GraphPad Prism (v5, GraphPad Software, San Diego, California) and IBM SPSS (v23, IBM, Armonk, New York). Data distributions were tested for normality by using the Kolmogorov- 
Smirnov test. For comparisons of 2 groups, $t$ tests or MannWhitney tests were used for parametric and non-parametric data, respectively. The chi-square test or the Fisher exact test was used to compare the frequencies between different groups. A subgroup analysis was performed to evaluate the prescription of ambulatory oxygen therapy among those with exertional desaturation. A backward stepwise multiple logistic regression was used to identify independent predictors for prescription of ambulatory oxygen therapy.

The selection of variables entered in the model was based on factors considered to influence the prescription of ambulatory oxygen therapy as well as on variables with $P<.10$ on the univariate logistic analyses. Before inclusion, the Pearson correlation was performed to detect predictors that were highly correlated to avoid multicollinearity. If the Pearson correlation coefficient was $\geq 0.60$ or the variance inflation factor was $>5$, then the predictor that was most significant in the univariate logistic analyses was entered into the model. Given the potential differences in clinical practice and test protocols, the study center was chosen a priori to be included as a fixed-effect variable. Data were expressed as mean \pm SD or median (interquartile range) as appropriate. Categorical variables were expressed as absolute number (percentage). Statistical significance was accepted as $P$ values $<.05$.

\section{Results}

Of 536 patients identified for the study, 136 were excluded because baseline 6MWTs were not performed. Data from 400 subjects (299 from Alfred Health and 101 from Austin Health) were included for analysis. Baseline demographic characteristics are presented in the supplementary materials (see http://www.rcjournal.com). The subjects from Austin Health were slightly older, had a higher rate of cardiorespiratory comorbidities (including asthma, COPD, pulmonary embolism, pulmonary hypertension, and any cardiac diseases), and had a shorter mean 6-min walk distance. Their nadir $\mathrm{S}_{\mathrm{pO}_{2}}$ during 6MWTs was higher. There were no significant differences in the frequencies of the types of ILD between the 2 centers (see the supplementary materials at http://www.rcjournal.com). The most common diagnoses were idiopathic pulmonary fibrosis, chronic hypersensitivity pneumonitis, and connective tissue disease related ILD.

\section{Prevalence of Exertional Desaturation}

Overall, the prevalence of exertional desaturation was $54 \%$ at baseline. It was significantly more prevalent in the subjects with more-severe lung function impairment as measured by FVC (Fig. 1) and diffusing capacity of the lung for carbon monoxide (Fig. 2). There were no significant differences in the prevalence rates of exertional de-

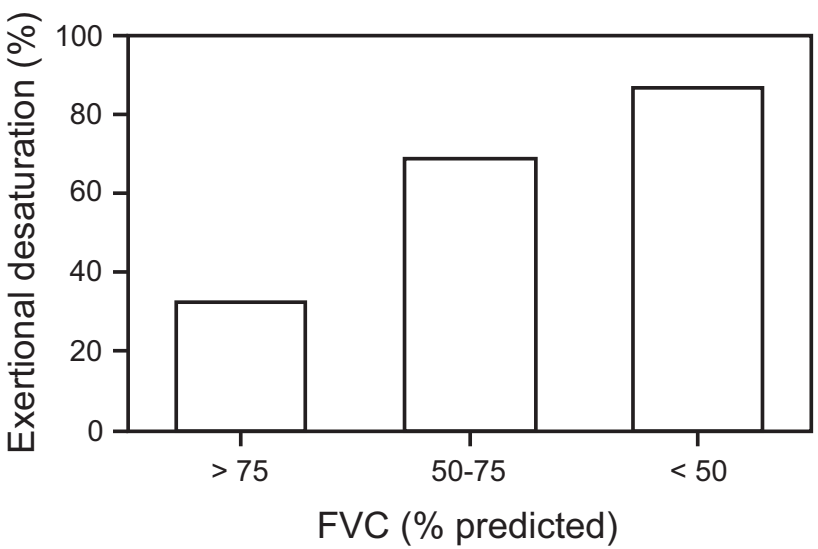

Fig. 1. Prevalence of exertional desaturation based on FVC $(P<$ .001).

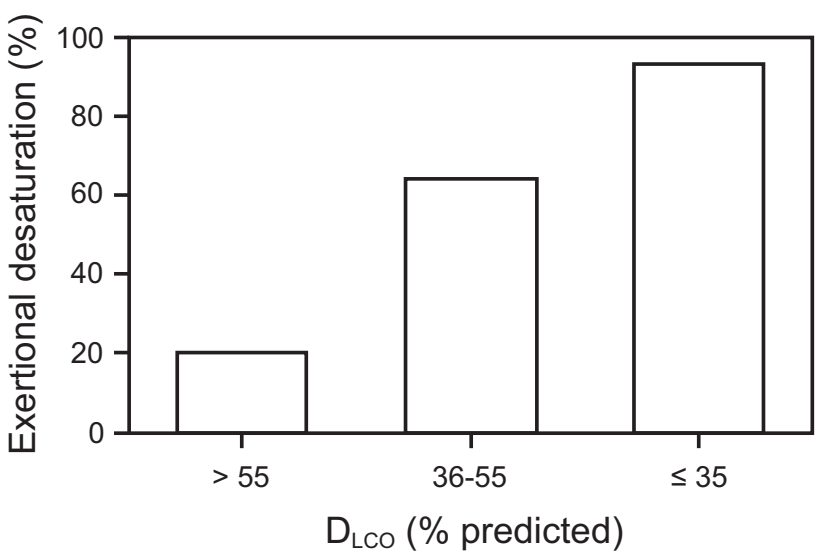

Fig. 2. Prevalence of exertional desaturation based on diffusing capacity of the lung for carbon monoxide $\left(D_{\text {LCO }}\right)(P<.001)$.

saturation among common types of ILD encountered in the clinics (idiopathic pulmonary fibrosis, 83/134 [62\%]; chronic hypersensitivity pneumonia, $37 / 57$ [65\%]; connective tissue disease-related ILD, 21/44 [48\%]; $P=.17$ ). The subjects with idiopathic pulmonary fibrosis and chronic hypersensitivity pneumonitis had lower nadir $\mathrm{S}_{\mathrm{pO}_{2}}$ compared with those with connective tissue disease related ILD median nadir $\mathrm{S}_{\mathrm{pO}_{2}}$ : idiopathic pulmonary fibrosis $=85$ $(81,91) \%$, chronic hypersensitivity pneumonitis $=84.5$ $(79,90) \%$, connective tissue disease-related ILD $=90$ $(84,94) \%$, data in parenthesis represents interquartile range $(P=.01)$.

\section{Characteristics of Patients With Exertional Desaturation}

The characteristics of the subjects according to the presence or absence of exertional desaturation at baseline are summarized in Table 1. The subjects with exertional desaturation were older and male predominant. The 6-min 


\section{Exertional Desaturation and Ambulatory Oxygen IN ILD}

Table 1. Baseline Subject Demographic Characteristics According to Exertional Desaturation at Baseline

\begin{tabular}{|c|c|c|c|}
\hline & Desaturator $(n=214)$ & Non-Desaturator $(n=186)$ & $P$ \\
\hline Age, mean \pm SD y & $67 \pm 10$ & $64 \pm 13$ & .02 \\
\hline Male, $\%$ & 68 & 48 & .001 \\
\hline \multicolumn{4}{|l|}{ Smoking history, $\%$} \\
\hline Ever smoker & 70 & 60 & .045 \\
\hline Never smoker & 30 & 40 & \\
\hline Co-existing cardiorespiratory comorbidities, $\% *$ & 51 & 42 & .09 \\
\hline $\mathrm{BMI}$, mean $\pm \mathrm{SD} \mathrm{kg} / \mathrm{m}^{2}$ & $28.9 \pm 5.5$ & $29.6 \pm 6.2$ & .43 \\
\hline $\mathrm{FEV}_{1}$, mean $\pm \mathrm{SD} \%$ predicted & $71.8 \pm 18.2$ & $84.4 \pm 17.0$ & $<.001$ \\
\hline $\mathrm{FVC}$, mean $\pm \mathrm{SD} \%$ predicted & $66.1 \pm 16.9$ & $82.6 \pm 17.9$ & $<.001$ \\
\hline $\mathrm{D}_{\mathrm{LCO}}$ mean $\pm \mathrm{SD} \%$ predicted & $41.1 \pm 12.1$ & $66.8 \pm 19.9$ & $<.001$ \\
\hline 6MWD, median (IQR) m & $411(302-497)$ & $450(360-532)$ & $<.001$ \\
\hline $6 \mathrm{MWT}$ resting $\mathrm{S}_{\mathrm{pO}_{2}}$, median (IQR) $\%$ & $94(9-96)$ & 97 (96-98) & $<.001$ \\
\hline $6 \mathrm{MWT}$ nadir $\mathrm{S}_{\mathrm{pO}_{2}}$, median (IQR) $\%$ & $82(78-85)$ & $93(91-95)$ & $<.001$ \\
\hline mMRC dyspnea scale, median (IQR) & $2(1-3)$ & $2(1-2)$ & $<.001$ \\
\hline \multicolumn{4}{|l|}{ SGRQ, median (IQR) } \\
\hline Symptom score & $62.9(45.3-77.9)$ & $44.5(25.5-69.5)$ & $<.001$ \\
\hline Activity score & $71.1(54.7-85.8)$ & $55.5(29.4-72.8)$ & $<.001$ \\
\hline Impact score & $39.7(25.3-57.6)$ & $25.7(11.4-49.4)$ & $<.001$ \\
\hline Total score & $54.0(39.6-66.5)$ & $40.3(20.4-61.0)$ & $<.001$ \\
\hline UCSD-SOBQ, median (IQR) & $44(28-67)$ & $29(13-53)$ & $<.001$ \\
\hline $\begin{array}{l}\text { *Includes asthma, COPD, pulmonary embolism, pulmonary hype } \\
\text { BMI = body mass index } \\
\text { D }_{\text {LCO }}=\text { diffusion capacity of the lung for carbon monoxide } \\
\text { IQR }=\text { interquartile range } \\
6 \text { MWD }=6 \text {-min walk distance } \\
6 \text { MWT }=6 \text {-min walk test } \\
\text { mMRC = modified Medical Research Council } \\
\text { SGRQ = St George's Respiratory Questionnaire } \\
\text { USCD-SOBQ = University of California San Diego Shortness of }\end{array}$ & cardiac diseases. & & \\
\hline
\end{tabular}

walk distance was significantly shorter in those who become desaturated. The subjects with exertional desaturation reported worse dyspnea, when measured by the modified Medical Research Council dyspnea scale and the University of California San Diego Shortness of Breath Questionnaire. Those who become desaturated also had poorer health-related quality of life with higher median $\mathrm{St}$ George Respiratory Questionnaire domain and total scores.

\section{Ambulatory Oxygen Therapy in Patients With Exertional Desaturation}

Fourteen of the 214 subjects $(7 \%)$ with exertional desaturation fulfilled the criteria for resting hypoxemia $\left(\mathrm{P}_{\mathrm{aO}_{2}}\right)$ of $\leq 55 \mathrm{~mm} \mathrm{Hg}$ or $\mathrm{P}_{\mathrm{aO}_{2}}$ of $56-59 \mathrm{~mm} \mathrm{Hg}$, with evidence of hypoxic organ damage) and were prescribed for longterm oxygen therapy. Of the 200 subjects with exertional desaturation but without resting hypoxemia, 58 (29\%) were prescribed ambulatory oxygen therapy. The prescription rates of ambulatory oxygen therapy were $28 \%(42 / 157)$ and $37 \%$ (16/43) for Alfred Health and Austin Health, respectively $(P=.19)$.
Those who were prescribed ambulatory oxygen therapy were predominantly female and had worse lung function impairment and symptoms, reduced distance walked, and lower resting and nadir $\mathrm{S}_{\mathrm{pO}_{2}}$ during 6MWTs (Table 2). Multiple logistic regression was used to identify factors that were significantly related to the prescription of ambulatory oxygen therapy. The variables considered in the complete model analysis are shown in Table 3 and in the multicollinearity assessment for the variables are shown in Tables 4 and 5 . The variables included for multiple logistic regression were study center, FVC (\% predicted), diffusing capacity of the lung for carbon monoxide (\% predicted), St George Respiratory Questionnaire activity score, 6-min walk distance, and resting and nadir $\mathrm{S}_{\mathrm{pO}_{2}}$ during 6MWTs. Multiple logistic regression showed independent associations between ambulatory oxygen therapy prescription and shorter 6-min walk distance $(P<.001)$ and worse FVC (\% predicted, $P=.037$ ) (Table 6).

\section{Discussion}

We found that exertional desaturation was common in the subjects with ILD who attended specialized ILD cen- 


\section{Exertional Desaturation and Ambulatory Oxygen in ILD}

Table 2. Baseline Subject Demographic Characteristics Based on the Prescription of Ambulatory Oxygen Therapy

\begin{tabular}{|c|c|c|c|}
\hline Characteristic & $\begin{array}{l}\text { With Ambulatory Oxygen } \\
\text { Therapy }(n=58)\end{array}$ & $\begin{array}{l}\text { Without Ambulatory Oxygen } \\
\text { Therapy }(n=142)\end{array}$ & $P$ \\
\hline Age, mean $\pm \mathrm{SD}$ y & $68 \pm 9$ & $67 \pm 10$ & .43 \\
\hline Male $\%$ & 34 & 71 & $<.001$ \\
\hline \multicolumn{4}{|l|}{ Smoking history $\%$} \\
\hline Ever smoker & 44 & 97 & .31 \\
\hline Never smoker & 14 & 45 & \\
\hline Co-existing cardiorespiratory comorbidities $\% *$ & 60 & 48 & .12 \\
\hline $\mathrm{BMI}$, mean $\pm \mathrm{SD} \mathrm{kg} / \mathrm{m}^{2}$ & $29.6 \pm 5.4$ & $28.7 \pm 5.4$ & .25 \\
\hline $\mathrm{FEV}_{1}$, mean $\pm \mathrm{SD} \%$ predicted & $67.3 \pm 17.0$ & $74.1 \pm 18.1$ & .02 \\
\hline $\mathrm{FVC}$, mean $\pm \mathrm{SD} \%$ predicted & $60.6 \pm 14.4$ & $68.7 \pm 16.7$ & .003 \\
\hline $\mathrm{D}_{\mathrm{LCO}}$, mean $\pm \mathrm{SD} \%$ predicted & $36.9 \pm 10.6$ & $43.3 \pm 12.3$ & .003 \\
\hline 6MWD, median (IQR) m & $341(234-422)$ & $450(338-530)$ & $<.001$ \\
\hline $6 \mathrm{MWT}$ resting saturation, median (IQR) \% & $93(92-95)$ & $95(93-96)$ & $<.001$ \\
\hline 6MWT nadir saturation, median (IQR) \% & $80(77-84)$ & $83(78-85)$ & .004 \\
\hline mMRC dyspnea scale score, median (IQR) & $2.5(2-3)$ & $2(1-2)$ & $<.001$ \\
\hline \multicolumn{4}{|l|}{ SGRQ, median (IQR) } \\
\hline Symptom score & $64.8(43.3-81.7)$ & $62.1(44.2-76.8)$ & .29 \\
\hline Activity score & $85.8(66.3-92.5)$ & $66.2(53.5-79.7)$ & $<.001$ \\
\hline Impact score & $47.2(34.0-63.3)$ & $35.3(23.4-51.9)$ & .01 \\
\hline Total score & $61.7(49.4-73.4)$ & $49.2(37.9-64.3)$ & .004 \\
\hline UCSD-SOBQ, median (IQR) & $65(43-84)$ & $39(23-58)$ & $<.001$ \\
\hline $\begin{array}{l}\text { *Includes asthma, COPD, pulmonary embolism, pulmonary hyl } \\
\text { BMI = body mass index } \\
\text { D } \text { DLO }_{\text {LCO diffusion capacity of the lung for carbon monoxide }} \\
\text { IQR }=\text { interquartile range } \\
\text { 6MWD }=6 \text {-min walk distance } \\
\text { 6MWT = 6-min walk test } \\
\text { mMRC = modified Medical Research Council } \\
\text { SGRQ = St George's Respiratory Questionnaire } \\
\text { USCD-SOBQ = University of California San Diego Shortness }\end{array}$ & any cardiac diseases. & & \\
\hline
\end{tabular}

ters, with a prevalence that ranged from $20 \%$ to $33 \%$ in subjects with mild lung function impairment to $86 \%$ to $93 \%$ in those with severe impairment. There was no significant difference in the prevalence of exertional desaturation among common disease subtypes encountered clinically. Ambulatory oxygen therapy was prescribed for one third of the subjects with ILD and exertional desaturation. Independent predictors of the prescription were worse lung function and reduced functional exercise capacity.

A previous study of nocturnal desaturation in a group of subjects with various types of ILD reported $47 \%$ of the 99 participants who performed 6MWTs and become desaturated to $\leq 88 \%$. ${ }^{14}$ The prevalence of exertional desaturation has been reported to be $47 \%$ to $53 \%$ in unselected patients with idiopathic pulmonary fibrosis and biopsyproven usual interstitial pneumonia.4,15 Data on patients with other types of ILD are scarce. To date, this was the largest cohort study to our knowledge that examined the prevalence of exertional desaturation in an unselected population of ILD. There was a high prevalence of exertional desaturation across different stages of ILD in our study, including those with preserved lung function. Exercise test- ing should be considered in all patients with ILD to identify the presence of exertional desaturation. Although there currently is no proven specific management for exertional desaturation in ILD, it is important to identify this phenomenon given that it aids in risk stratification, predicting prognosis, and identifying patients for lung transplantation referral.

The mechanisms that cause exertional desaturation in ILD are complex, with multiple factors contributing to varying degrees. Ventilation-perfusion mismatch in the lungs seems to be the predominant factor for exertional desaturation in ILD. ${ }^{16}$ Pulmonary diffusion limitation with decreased pulmonary capillary transit time during exertion also contributes to a significant degree. ${ }^{16,17}$ Low mixed venous oxygen concentration due to reduced cardiac output and proportionately increased tissue oxygen extraction is observed in patients with ILD during exertion. ${ }^{16}$ The presence of pulmonary hypertension in some patients with ILD can further add to the burden of gas exchange and circulatory impairment during exertion. ${ }^{18,19}$ Exertional desaturation has also been shown to correlate with the morphology of ILD. ${ }^{17,19-22}$ The prevalence rates of exertional desaturation among common types of ILD were similar in 


\section{Exertional Desaturation and Ambulatory Oxygen in ILD}

Table 3. Univariate Logistic Analysis for Variables Considered for Multiple Logistic Regression

\begin{tabular}{lcc}
\hline \multicolumn{1}{c}{ Variable } & Odds Ratio (95\% CI) & $P$ \\
\hline Age & $1.013(0.982-1.044)$ & .43 \\
Sex & $1.297(0.676-2.488)$ & .44 \\
Co-existing & $1.656(0.890-3.080)$ & .11 \\
$\quad$ cardiorespiratory & & \\
$\quad$ comorbidities & $0.979(0.960-0.998)$ & .03 \\
FEV ${ }_{1}, \%$ predicted & $0.968(0.946-0.990)$ & .004 \\
FVC, \% predicted & $0.954(0.924-0.984)$ & .003 \\
$\mathrm{D}_{\text {LCO }} \%$ predicted & $0.994(0.992-0.997)$ & $<.001$ \\
6MWD, m & $0.828(0.745-0.920)$ & $<.001$ \\
6MWT resting saturation, \% & $0.920(0.863-0.981)$ & .01 \\
6MWT nadir saturation, \% & $1.810(1.278-2.563)$ & .001 \\
mMRC dyspnea scale & & \\
SGRQ & $1.000(1.000-1.000)$ & .66 \\
$\quad$ Symptom score & $1.043(1.021-1.065)$ & $<.001$ \\
$\quad$ Activity score & $1.020(1.004-1.037)$ & .02 \\
Impact score & $1.030(1.009-1.051)$ & .005 \\
$\quad$ Total score & $1.036(1.021-1.052)$ & $<.001$ \\
UCSD-SOBQ & $1.623(0.796-3.308)$ & .18 \\
Study site & & \\
\hline DLCO = diffusion capacity of the lung for carbon monoxide & \\
6MWD = 6-min walk distance & & \\
6MWT = 6-min walk test \\
mMRC = modified Medical Research Council \\
SGRQ = St George's Respiratory Questionnaire \\
USCD-SOBQ = University of California San Diego Shortness of Breath Questionnaire \\
\hline
\end{tabular}

Table 4. Multicollinearity Assessment of Variables Considered for Inclusion in Multiple Logistic Regression: Correlations of Variables $(r \geq 0.60)$

\begin{tabular}{llc}
\hline \hline Variable Considered & \multicolumn{1}{c}{ Correlated With } & Correlation Coefficient \\
\hline FEV $_{1}, \%$ predicted & FVC, \% predicted & 0.91 \\
mMRC dyspnea & SGRQ, activity score & 0.66 \\
\multicolumn{1}{c}{ scale } & SGRQ, total score & 0.64 \\
& UCSD-SOBQ & 0.63 \\
SGRQ, activity score & SGRQ, impact score & 0.75 \\
& SGRQ, total score & 0.87 \\
& UCSD-SOBQ & 0.79 \\
SGRQ, impact score & SGRQ, total score & 0.96 \\
& UCSD-SOBQ & 0.77 \\
SGRQ, total score & UCSD-SOBQ & 0.81
\end{tabular}

$\overline{\mathrm{mMRC}}=$ modified Medical Research Council

SGRQ $=$ St George's Respiratory Questionnaire

USCD-SOBQ = University of California San Diego Shortness of Breath Questionnaire

our study, although the subjects with idiopathic pulmonary fibrosis and chronic hypersensitivity pneumonitis had a lower nadir $\mathrm{S}_{\mathrm{pO}_{2}}$ than those with connective tissue diseaseILD.

Recent randomized controlled trials of pirfenidone in subjects with idiopathic pulmonary fibrosis reported that
Table 5. Multicollinearity Assessment of Variables Considered for Inclusion in Multiple Logistic Regression: Variance Inflation Factors for Variables $(\geq 5)$

\begin{tabular}{lc}
\hline \hline Variable Considered & Variance Inflation Factor \\
\hline SGRQ & \\
Activity score & 9.2 \\
Impact score & 26.8 \\
Total score & 45.1 \\
& \\
\hline SGRQ $=$ St George's Respiratory Questionnaire & \\
\hline
\end{tabular}

Table 6. Multiple Logistic Regression for Prescription of Ambulatory Oxygen Therapy in Subjects With Exertional Desaturation

\begin{tabular}{llr}
\hline \hline \multicolumn{1}{c}{ Variable } & Odds Ratio (95\% CI) & $P$ \\
\hline FVC, \% predicted & $0.970(0.943-0.998)$ & .037 \\
6MWD, m & $0.993(0.990-0.997)$ & $<.001$ \\
\hline 6MWD $=$ 6-min walk distance & & \\
\hline
\end{tabular}

$21 \%$ to $28 \%$ of trial participants were prescribed supplemental oxygen therapy. ${ }^{23,24}$ A Danish cohort study of 121 subjects with idiopathic pulmonary fibrosis found that $55 \%$ were prescribed supplemental oxygen therapy. ${ }^{25}$ These reported rates included both long-term oxygen therapy and ambulatory oxygen therapy. In the current study, $29 \%$ of the participants with isolated exertional desaturation were prescribed ambulatory oxygen therapy. There are limited data on the prescription rates of ambulatory oxygen therapy in other chronic lung diseases. A prospective cohort study of primary care subjects with COPD reported that $2.5 \%$ were prescribed ambulatory oxygen therapy. ${ }^{26}$ Randomized controlled trials of tiotropium in subjects with COPD reported a similar rate of $1.9 \%$ to $4.2 \%$ of the participants being prescribed supplemental oxygen therapy. ${ }^{27,28}$ Differences in service provision with inequitable access to oxygen therapy across jurisdictions may influence varying prescription rates of ambulatory oxygen therapy.

Although exertional desaturation is associated with worse prognosis in ILD, the long-term effects of ambulatory oxygen therapy to improve oxygenation during exertion have not been studied. Guidelines for provision of ambulatory oxygen therapy vary nationally and internationally. $8,9,29$ The threshold for prescription of ambulatory oxygen therapy for patients with ILD is uncertain. Patient preference was identified as an important determining factor for prescription of oxygen therapy in ILD. ${ }^{30}$ A previous study of ambulatory oxygen therapy in subjects with severe COPD and isolated exertional desaturation showed that a significant proportion of subjects (41\%) declined 
ongoing use of the therapy after study completion. ${ }^{31}$ In this study, the prescription of ambulatory oxygen therapy was associated with worse lung function and functional exercise capacity. This substantiates our previous findings that patients would like to delay the use of ambulatory oxygen therapy until more-advanced stages of their illness. ${ }^{32}$ It is uncertain whether a delay in the initiation of ambulatory oxygen therapy in patients with ILD and exertional desaturation will impact disease progression and prognosis.

Various definitions of exertional desaturation have been used in different trials in ILD, including a nadir $\mathrm{S}_{\mathrm{pO}_{2}}$ of $\leq 88 \% 2,15$ and a decrease in $\mathrm{S}_{\mathrm{pO}_{2}}$ of at least $4 \%$ with or without a nadir $\mathrm{S}_{\mathrm{pO}_{2}}<90 \% .33-35 \mathrm{~A}$ fall in $\mathrm{S}_{\mathrm{pO}_{2}}$ to $\leq 88 \%$ during exercise was chosen for this study, given that it is a common criterion used for consideration of prescribing ambulatory oxygen therapy in different countries, including Australia. More importantly, this degree of desaturation during exercise tests has been shown to be an important predictor of morbidity and mortality in patients with ILD. ${ }^{2,4,5,7}$ Similarly, there is no accepted standard diagnostic test for assessment of exertional desaturation. Different test modalities have been shown to influence the degree of desaturation. Compared with cycle tests, walking tests are more sensitive for detecting exertional desaturation. ${ }^{36-38}$ The $6 \mathrm{MWT}$ is a simple and inexpensive test, which is widely used in both clinical and trial settings with a standardized test protocol and well-researched measurements. In addition, because the 6WMT is self-paced, it is well tolerated and more reflective of daily activities than other exercise tests. ${ }^{35,39,40}$ Although the variation in the number of 6MWTs conducted at both centers may account for the differences in 6-min walk distance due to the learning effect, ${ }^{13}$ it is not known to impact on the degree of oxygen desaturation.

Our study had several limitations. It was conducted in specialized ILD centers, which may limit its generalizability, given that the study population may differ from those in other clinical settings. Although the retrospective design is a limitation, we included subjects with various diagnoses and degrees of disease severity who had undergone baseline 6MWTs to reflect a real-world clinical setting. Given the lack of uniform definition of exertional desaturation, our findings cannot be extrapolated to patient data by using different definitions of exertional desaturation or different exercise tests. The prescribing practice for ambulatory oxygen therapy at our centers may not reflect the practice of other physicians; nevertheless, there were several respiratory physicians who worked at these specialized ILD centers.

\section{Conclusions}

Exertional desaturation is common in patients with ILD, even in those with mild physiologic impairment. Given the prevalence and significance of exertional desaturation, routine evaluation should be considered. This study provided insights into the prescription of ambulatory oxygen therapy for patients with ILD and exertional desaturation. Ambulatory oxygen therapy was prescribed for only a small proportion of patients with ILD and exertional desaturation. Its prescription was associated with more severely impaired lung function and worse functional exercise capacity. The prospective evaluation of long-term effects of ambulatory oxygen therapy in patients with ILD will provide essential information to improve and guide our practice.

\section{REFERENCES}

1. King TE Jr, Tooze JA, Schwarz MI, Brown KR, Cherniack RM. Predicting survival in idiopathic pulmonary fibrosis: scoring system and survival model. Am J Respir Crit Care Med 2001;164(7):11711181.

2. Lama VN, Flaherty KR, Toews GB, Colby TV, Travis WD, Long Q, et al. Prognostic value of desaturation during a 6-minute walk test in idiopathic interstitial pneumonia. Am J Respir Crit Care Med 2003; 168(9):1084-1090.

3. Hallstrand TS, Boitano LJ, Johnson WC, Spada CA, Hayes JG, Raghu G. The timed walk test as a measure of severity and survival in idiopathic pulmonary fibrosis. Eur Respir J 2005;25(1):96-103.

4. Flaherty KR, Andrei AC, Murray S, Fraley C, Colby TV, Travis WD, et al. Idiopathic pulmonary fibrosis: prognostic value of changes in physiology and six-minute-walk test. Am J Respir Crit Care Med 2006;174(7):803-809.

5. Wallaert B, Monge E, Le Rouzic O, Wémeau-Stervinou L, Salleron J, Grosbois JM. Physical activity in daily life of patients with fibrotic idiopathic interstitial pneumonia. Chest 2013;144(5):1652-1658.

6. Herridge J, Yuill K, Kendrick AH. Does the six-minute walk test predict survival at one year and in the longer term in patients idiopathic pulmonary fibrosis (IPF)? Thorax 2016;71(Suppl 3):A239A240.

7. Nishiyama O, Taniguchi H, Kondoh Y, Kimura T, Kato K, Ogawa $\mathrm{T}$, et al. Dyspnoea at 6-min walk test in idiopathic pulmonary fibrosis: comparison with COPD. Resp Med 2007;101(4):833-838.

8. Hardinge M, Annandale J, Bourne S, Cooper B, Evans A, Freeman D, et al; British Thoracic Society Home Oxygen Guideline Development Group; British Thoracic Society Standards of Care Committee. British Thoracic Society guidelines for home oxygen use in adults. Thorax 2015;70(Suppl 1):i1-i43.

9. McDonald CF, Whyte K, Jenkins S, Serginson J, Frith P. Clinical practice guideline on adult domiciliary oxygen therapy: executive summary from the Thoracic Society of Australia and New Zealand. Respirology 2016;21(1):76-78.

10. Sharp C, Adamali H, Millar AB. Ambulatory and short-burst oxygen for interstitial lung disease. Cochrane Database Syst Rev 2016;7: CD011716.

11. Bell EC, Cox NS, Goh N, Glaspole I, Westall GP, Watson A, Holland AE. Oxygen therapy for interstitial lung disease: a systematic review. Eur Respir Rev 2017;26(143). pii: 160080.

12. Visca D, Mori L, Tsipouri V, Canu S, Bonini M, Pavitt M, et al. AmbOx: a randomised controlled, crossover trial evaluating the effects of ambulatory oxygen on health status in patients with fibrotic interstitial lung disease. Am J Resp Crit Care 2017;195:A7603.

13. Holland AE, Spruit MA, Troosters T, Puhan MA, Pepin V, Saey D, et al. An official European Respiratory Society/American Thoracic 


\section{Exertional Desaturation and Ambulatory Oxygen IN ILD}

Society technical standard: field walking tests in chronic respiratory disease. Eur Respir J 2014;44(6):1428-1446.

14. Corte TJ, Wort SJ, Talbot S, Macdonald PM, Hansell DM, Polkey $\mathrm{M}$, et al. Elevated nocturnal desaturation index predicts mortality in interstitial lung disease. Sarcoidosis Vasc Diffuse Lung Dis 2012; 29(1):41-50.

15. Lettieri CJ, Nathan SD, Browning RF, Barnett SD, Ahmad S, Shorr $\mathrm{AF}$. The distance-saturation product predicts mortality in idiopathic pulmonary fibrosis. Respir Med 2006;100(10):1734-1741.

16. Agustí AG, Roca J, Gea J, Wagner PD, Xaubet A, Rodriguez-Roisin R. Mechanisms of gas-exchange impairment in idiopathic pulmonary fibrosis. Am Rev Respir Dis 1991;143(2):219-225.

17. Risk C, Epler GR, Gaensler EA. Exercise alveolar-arterial oxygen pressure difference in interstitial lung disease. Chest 1984;85(1): 69-74.

18. Raghu G, Nathan SD, Behr J, Brown KK, Egan JJ, Kawut SM, et al. Pulmonary hypertension in idiopathic pulmonary fibrosis with mildto-moderate restriction. Eur Respir J 2015;46(5):1370-1377.

19. Boutou AK, Pitsiou GG, Trigonis I, Papakosta D, Kontou PK, Chavouzis $\mathrm{N}$, et al. Exercise capacity in idiopathic pulmonary fibrosis: the effect of pulmonary hypertension. Respirology 2011;16(3):451458.

20. Fulmer JD, Roberts WC, von Gal ER, Crystal RG. Morphologicphysiologic correlates of the severity of fibrosis and degree of cellularity in idiopathic pulmonary fibrosis. J Clin Invest 1979;63(4): 665-676.

21. Agusti AG, Roca J, Rodriguez-Roisin R, Xaubet A, Agusti-Vidal A. Different patterns of gas exchange response to exercise in asbestosis and idiopathic pulmonary fibrosis. Eur Respir J 1988;1(6):510-516.

22. Chinet T, Jaubert F, Dusser D, Danel C, Chrétien J, Huchon GJ. Effects of inflammation and fibrosis on pulmonary function in diffuse lung fibrosis. Thorax 1990;45(9):675-678.

23. Noble PW, Albera C, Bradford WZ, Costabel U, Glassberg MK, Kardatzke D, et al.; CAPACITY Study Group. Pirfenidone in patients with idiopathic pulmonary fibrosis (CAPACITY): two randomised trials. Lancet 2011;377(9779):1760-1769.

24. King TE Jr, Bradford WZ, Castro-Bernardini S, Fagan EA, Glaspole I, Glassberg MK, et al.; ASCEND Study Group. A phase 3 trial of pirfenidone in patients with idiopathic pulmonary fibrosis. N Engl J Med 2014;370(22):2083-2092.

25. Hyldgaard C. A cohort study of Danish patients with interstitial lung diseases: burden, severity, treatment and survival. Dan Med J 2015; 62(4):B5069.

26. Siebeling L, Puhan MA, Muggensturm P, Zoller M, Ter Riet G. Characteristics of Dutch and Swiss primary care COPD patients baseline data of the ICE COLD ERIC study. Clin Epidemiol 2011; 3:273-283.
27. Tashkin DP, Celli B, Senn S, Burkhart D, Kesten S, Menjoge S, Decramer M; UPLIFT Study Investigators. A 4-year trial of tiotropium in chronic obstructive pulmonary disease. N Engl J Med 2008; 359(15):1543-1554.

28. Wise RA, Anzueto A, Cotton D, Dahl R, Devins T, Disse B; TIOSPIR Investigators. Tiotropium Respimat inhaler and the risk of death in COPD. N Engl J Med 2013;369(16):1491-1501.

29. Lacasse Y, Bernard S, Maltais F. Eligibility for home oxygen programs and funding across Canada. Can Respir J 2015;22(6):324-330.

30. Khor YH, Goh NSL, McDonald CF, Holland AE. Oxygen therapy for interstitial lung disease: physicians' perceptions and experiences. Ann Am Thorac Soc 2017;14(12):1772-1778.

31. Eaton T, Garrett JE, Young P, Fergusson W, Kolbe J, Rudkin S, Whyte K. Ambulatory oxygen improves quality of life of COPD patients: a randomised controlled study. Eur Respir J 2002;20(2): 306-312.

32. Khor YH, Goh NSL, McDonald CF, Holland AE. Oxygen therapy for interstitial lung disease: a mismatch between patient expectations and experiences. Ann Am Thorac Soc 2017;14(6):888-895.

33. Villalba WO, Sampaio-Barros PD, Pereira MC, Cerqueira EM, Leme CA Jr., Marques-Neto JF, Paschoal IA. Six-minute walk test for the evaluation of pulmonary disease severity in scleroderma patients. Chest 2007;131(1):217-222.

34. Delourme J, Stervinou-Wemeau L, Salleron J, Grosbois JM, Wallaert B. Six-minute stepper test to assess effort intolerance in interstitial lung diseases. Sarcoidosis Vasc Diffuse Lung Dis 2012;29(2): 107-112.

35. Jenkins S, Čečins N. Six-minute walk test: observed adverse events and oxygen desaturation in a large cohort of patients with chronic lung disease. Intern Med J 2011;41(5):416-422.

36. Poulain M, Durand F, Palomba B, Ceugniet F, Desplan J, Varray A, Préfaut C. 6-minute walk testing is more sensitive than maximal incremental cycle testing for detecting oxygen desaturation in patients with COPD. Chest 2003;123(5):1401-1407.

37. Hsia D, Casaburi R, Pradhan A, Torres E, Porszasz. Physiological responses to linear treadmill and cycle ergometer exercise in COPD. Eur Respir J 2009;34(3):605-615.

38. Mahler DA, Gifford AH, Waterman LA, Ward J, Machala S, Baird JC. Mechanisms of greater oxygen desaturation during walking compared with cycling in patients with COPD. Chest 2011;140(2):351358.

39. Solway S, Brooks D, Lacasse Y, Thomas S. A qualitative systematic overview of the measurement properties of functional walk tests used in the cardiorespiratory domain. Chest 2001;119(1):256-270.

40. Enright PL, McBurnie MA, Bittner V, Tracy RP, McNamara R, Arnold A, Newman AB; Cardiovascular Health Study. The 6-min walk test: a quick measure of functional status in elderly adults. Chest 2003;123(2):387-398. 